\title{
Avaliação do Socrative App como ferramenta auxiliar de ensino para a construção de aprendizagens significativas em uma disciplina de física geral a partir do Peer Instruction
}

\author{
Marcelo Vettori' ${ }^{1}$, Milton Antônio Zaro \\ ${ }^{1}$ PPGIE - Universidade Federal do Rio Grande do Sul (UFRGS) \\ Av. Paulo Gama, 110 - prédio 12105 - $3^{\circ}$ andar sala 332 \\ 90040-060 - Porto Alegre (RS) - Brasil \\ ${ }^{2}$ PPGIE - Universidade Federal do Rio Grande do Sul (UFRGS) \\ mvettoriegmail.com, zarodufrgs.br
}

\begin{abstract}
The article aims to present the results of an evaluation about the use of the Socrative App as a teaching tool for building meaningful learning, working with Peer Instruction as active methodology. In this case study the investigation subjects evaluated the app with essay questions. The results suggest that the app, with practiced methodology, contributes to a change in behavior motivated by the use of that technology.
\end{abstract}

Resumo. $O$ artigo tem como objetivo apresentar os resultados de uma avaliação sobre o uso do Socrative App como ferramenta auxiliar de ensino para a construção de aprendizagens significativas, utilizando o Peer Instruction como metodologia ativa. Trata-se de um estudo de caso no qual os sujeitos avaliaram esse aplicativo por meio de um questionário com questões dissertativas. Os resultados sugerem que esse aplicativo, aliado a metodologia praticada, favorece a uma mudança de comportamento motivada pelo uso dessa tecnologia.

\section{Introdução}

As ferramentas de ensino podem variar do giz ao apagador, do quadro-negro ao projetor, dos laboratórios de ciências aos dispositivos móveis, entre outros. Essas ferramentas, quando apoiadas a uma metodologia ativa de trabalho, podem favorecer $\mathrm{o}$ desenvolvimento de aprendizagens significativas de uma disciplina.

No caso dos dispositivos móveis, algumas experiências levadas para a sala de aula demonstram que é possível ensinar e aprender em diferentes contextos. Com aplicativos que vão de simuladores de experiências à gerenciadores de informações, passando por mensageiros instantâneos e redes sociais, professores e alunos conseguem dar um novo sentido à sala de aula. Segundo Moran (2013), aprendemos melhor quando vivenciamos, relacionamos, experimentamos, sentimos aquilo que aprendemos, estabelecendo vínculos, dando significado a um novo contexto para integrá-lo ao que conhecemos.

Nesse sentido, Alencar et al. (2015) realizaram um trabalho com o aplicativo WhatsApp como ferramenta de apoio ao ensino. Honorato et al (2015), utilizaram um 
V Congresso Brasileiro de Informática na Educação (CBIE 2016)

Anais do XXVII Simpósio Brasileiro de Informática na Educação (SBIE 2016)

simulador virtual sobre os vetores da física. Os resultados dessas pesquisas demonstram a importância de inovar e reinventar a sala de aula com métodos apropriados ao uso dessas tecnologias. Segundo Valente (1999), a utilização de inovações metodológicas exige mudanças nos processos de ensino e aprendizagem, que são muito mais profundas, especificamente com relação à sala de aula, ela terá de ser repensada na sua estrutura, bem como na abordagem pedagógica.

Neste trabalho apresentamos o Socrative App ${ }^{l}$, um software sem custos que está disponível na web e em lojas virtuais para dispositivos móveis. Esse aplicativo é uma ferramenta de ensino que apresenta possibilidades de ensinar e aprender com um celular ou tablet em sala de aula.

Com o Socrative, o professor visualiza em seu dispositivo móvel (ou desktop) as repostas das atividades dos alunos em sala de aula no exato instante em que são postadas. Essas atividades podem ser de múltipla escolha, verdadeiro/falso, respostas curtas e questões dissertativas. Além disso, é possível o professor elaborar e editar o seu próprio banco de questões, compartilhando com alunos e, também, com colegas de trabalho da mesma disciplina.

Além disso, pode-se usar o Socrative como instrumento de coleta de dados para organizar os conteúdos de acordo com os conhecimentos prévios dos alunos no sentido de concretizar, quando possível, aprendizagens significativas (AUSUBEL 1978, MOREIRA, 1999). É possível, ainda, trabalhar com metodologias ativas como o Peer Instrucion elaborada por MAZUR (2015) ou, em uma tradução livre, Instrução pelos Colegas (ARAUJO, 2013).

O aplicativo disponibiliza ao professor rever a compreensão dos alunos em diferentes modelos de relatórios: visão geral da classe inteira, resultados específicos de cada estudante e o percentual de acertos por questão. Todos os relatórios podem ser enviados diretamente do aplicativo para o e-mail do professor ou para a pasta Google Drive a qualquer momento. O próprio aplicativo também armazena os relatórios na seção Reports.

O objetivo deste trabalho é apresentar uma avaliação sobre o uso do Socrative como ferramenta auxiliar de ensino para a construção de aprendizagens significativas, a partir das respostas dos alunos de diferentes cursos de engenharia de uma universidade privada do sul do Brasil utilizando como metodologia ativa, o Peer Instruction,

Entendemos que a relevância desta pesquisa para a educação, assim como os trabalhos relacionados que citamos anteriormente (WhatsApp e Vetores), encontra-se nos resultados que destacam o engajamento e a motivação dos alunos entrevistados sobre o desenvolvimento de suas aprendizagens.

A seguir, apresentamos a fundamentação teórica baseada pelas ideias de Ausubel e Mazur. Na sequência abordamos a metodologia de pesquisa, um estudo de caso, seguida dos resultados e discussão sobre a avaliação do aplicativo descrito anteriormente. Por último, apresentamos as considerações finais deste trabalho, salientando a relevância do Socrative como uma ferramenta que favorece a construção de aprendizagens significativas com a implementação de uma metodologia ativa como o

\footnotetext{
${ }^{1}$ http://socrative.com
} 
V Congresso Brasileiro de Informática na Educação (CBIE 2016)

Anais do XXVII Simpósio Brasileiro de Informática na Educação (SBIE 2016)

Peer Instruction. Finalizamos o artigo apresentando as nossas futuras intenções no campo da neurociência com a finalidade de ampliarmos essa pesquisa.

\section{Fundamentação Teórica}

\subsection{A Aprendizagem Significativa de David Ausubel}

Ao concluir seus estudos em psiquiatria, Ausubel (1918-2008) dedicou-se à educação, tornando-se um dos expoentes da psicologia educacional. Propôs, nesse sentido, o desenvolvimento de uma aprendizagem baseada em um processo de armazenamento de informações que, incorporadas na mente do indivíduo, possam ser manipuladas através da organização e integração de conteúdos para que novas aprendizagens venham a ocorrer, portanto, aprendizagens significativas.

Segundo Ausubel (1978), uma aprendizagem é significativa quando faz algum sentido para o aprendiz. No processo de aprender a informação deverá interagir e ancorar-se em conceitos relevantes e existentes na estrutura cognitiva do aprendiz. $\mathrm{O}$ autor afirma, portanto, que o processo de aprendizagem desse aprendiz leve em conta o emprego de organizadores prévios para a ancoragem de uma nova aprendizagem. Os organizadores prévios são elementos que devem ser previamente apresentados em relação a novos conteúdos, servindo de ponte entre o que o estudante sabe e o que ele precisa saber para que ocorra uma aprendizagem significativa. Essa, por sua vez, conduzirá o estudante ao desenvolvimento de subsunçores, que possibilitarão a construção de aprendizagens futuras. De acordo com Moreira (1999) os subsunçores são conhecimentos específicos existentes na estrutura de conhecimentos do indivíduo, que permite dar significado a um novo conhecimento que lhe é apresentado ou por ele descoberto. A palavra subsunçor não existe na língua portuguesa. Foi criada a partir da língua inglesa subsumer que significa inseridor, facilitador ou subordinador (MOREIRA, 1999).

Para Ausubel (1978), são duas as condições básicas para que ocorra uma aprendizagem significativa. A primeira, o material didático que deve ser potencialmente significativo. A segunda, a disposição do aprendiz para aprender.

Um material potencialmente significativo não está em um livro e nem em uma aula, mas na pessoa que já está predisposta a aprender. Para Moreira (1999), não se trata exatamente de motivação, ou de gostar da matéria. Por alguma razão, o aprendiz deve se predispor a relacionar interativamente os novos conhecimentos a sua estrutura cognitiva prévia, modificando-a, enriquecendo-a, elaborando-a e dando significados a esses conhecimentos. Consequentemente, o material elaborado pelo professor será potencialmente significativo, pois possibilitará ao aprendiz relacionar os conteúdos a sua estrutura cognitiva de maneira não-arbitrária e não-literal.

\subsection{Peer Instruction}

Eric Mazur (1954 - atualmente) é físico da Universidade de Harvard e elaborou uma metodologia ativa conhecida como Peer Instruction. Esse método de trabalho é baseado na leitura prévia de materiais disponibilizados pelo professor e na apresentação de questões conceituais, em sala de aula, para os alunos discutirem entre si (ARAUJO e MAZUR, 2013). Nesse sentido, o Peer Instruction busca favorecer a aprendizagem de 
V Congresso Brasileiro de Informática na Educação (CBIE 2016)

Anais do XXVII Simpósio Brasileiro de Informática na Educação (SBIE 2016)

conceitos fundamentais dos conteúdos em estudo, através da interação entre os estudantes. A partir de uma breve exposição oral do professor e, na sequência é preciso que os alunos respondam questões de múltipla escolha, com o objetivo de avaliarem e compararem as suas compreensões.

Araujo e Mazur (2013) explicam que essas avaliações compreendem diferentes situações de acordo com as respostas dadas pelos alunos. Na primeira, para que o professor saiba o que cada aluno está individualmente pensando, um sistema de votação, como o Socrative pode ser utilizado, pois o feedback é imediato. Se o percentual de acerto das respostas for igual ou inferior a 30\%, o professor retoma o conceito com a turma. Se o percentual de acerto das respostas apresentadas estiverem acima de $30 \%$ e inferior a 70\%, o professor pede aos alunos que, em grupos de dois a cinco componentes, discutam as alternativas escolhidas, tentando convencer uns aos outros de suas diferentes escolhas. Porém, se mais de $70 \%$ das respostas estiverem corretas, uma breve explanação pode ser feita pelo professor que irá anunciar o próximo tópico ou apresentará uma nova questão referente ao mesmo conteúdo.

\section{Metodologia}

A pesquisa tem abordagem qualitativa e natureza descritiva, pois busca a relação de conhecimentos em relação a um fenômeno. É um estudo de caso, uma vez que decorre de acordo com uma perspectiva interpretativa, que procura compreender como é o mundo do ponto de vista dos participantes (YIN, 2010), ou uma perspectiva pragmática, que visa simplesmente apresentar uma perspectiva global, tanto quanto possível completa e coerente do objeto de estudo do ponto de vista do investigador (GIL, 2007).

Os sujeitos da pesquisa são 60 alunos de cinco turmas diferentes (12 por turma) dos cursos de engenharia de uma universidade privada da região sul do Brasil. Esses, cursaram a disciplina de física básica (mecânica) no segundo semestre de 2015. São 45 do sexo masculino e 15 do sexo feminino. As idades variam entre 17 e 21 anos para todos os entrevistados.

Os dados foram coletados e analisados através de um questionário com cinco questões e foi aplicado para os sujeitos avaliarem o uso do Socrative e as consequências em suas aprendizagens a partir da metodologia ativa Peer Instruction. Dessa forma, foi possível avaliar e verificar alguns indícios de aprendizagens significativas nesta etapa da vida acadêmica desses alunos. Dos 60 alunos que responderam a essas questões, escolhemos 20 que apresentaram respostas e argumentos próximos aos 40 sujeitos que não são citados neste artigo. Esses 20 alunos estão cientes desta pesquisa e aceitaram participar da mesma.

\section{Resultados e discussão}

Em cada tabela desta seção, apresentamos as questões do questionário aplicado e os percentuais das respostas. Abaixo dessas, cada aluno está identificado pela letra A mais um número, ambos entre parênteses. Os argumentos das respostas dadas pelos alunos seguem ao lado do código de identificação.

TABELA 1. Primeira questão com percentuais de respostas de SIM ou NÃO 
V Congresso Brasileiro de Informática na Educação (CBIE 2016)

Anais do XXVII Simpósio Brasileiro de Informática na Educação (SBIE 2016)

Você considera que o seu envolvimento e sua aprendizagem na disciplina aumentaram com o Socrative? Por que?

\begin{tabular}{|c|c|}
\hline SIM $(85 \%)$ & NÃO (15\%) \\
\hline $\begin{array}{l}\text { (A1) Porque consigo me envolver mais na aula. E } \\
\text { quando me envolvo mais, eu aprendo melhor. Fiquei } \\
\text { mais participativo. E mais, consigo relacionar } \\
\text { conceitos básicos para o entendimento do todo. } \\
\text { (A2) Porque depois que eu comecei a usar esse } \\
\text { aplicativo, notei que meu interesse em fazer as } \\
\text { questões aumentou. Fico na expectativa de chegar na } \\
\text { resposta. } \\
\text { (A3) As questões apresentadas pelo professor fazem } \\
\text { sentido e isso nos faz participar mais da aula. O } \\
\text { Socrative nos faz prestar mais atenção no que estamos } \\
\text { pensando e fazendo. }\end{array}$ & $\begin{array}{l}\text { (A4) Porque as minhas notas não mudaram. Eu } \\
\text { sempre tiro DEZ! Eu sei que pra alguns mudou, mas } \\
\text { como sempre fui bom aluno, pra mim nada mudou. } \\
\text { (A5) Porque eu não consigo entender muito bem a } \\
\text { matéria, assim. Prefiro que o professor dê aula o } \\
\text { tempo todo. Tudo é muito complexo e eu não sei nem } \\
\text { por onde começar. Não consigo entender as ideias dos } \\
\text { meus colegas. Fico de queixo caído com as relações } \\
\text { que eles fazem saindo de um caso simples para outro } \\
\text { mais complexo. Nem o simples eu entendo. } \\
\text { (A6) Porque as minhas notas continuaram baixas. O } \\
\text { exemplo disso é que dificilmente eu consigo ver o que } \\
\text { a maioria vê. } \\
\text { (A7) Porque eu só consigo fazer as questões teóricas, } \\
\text { as de cálculo, eu patino. }\end{array}$ \\
\hline
\end{tabular}

A partir da tabela 1, é possível perceber que os argumentos dos $85 \%$ que responderam SIM, demonstram que o aplicativo favoreceu o envolvimento em sala de aula, uma vez que o entendimento dos conteúdos e das questões trabalhadas os fazem relacionar os conceitos básicos para a compreensão do todo (A1). Esse argumento é um possível indício de que possam ter ocorrido aprendizagens significativas, uma vez que essas são possibilitadas a partir dos conhecimentos prévios dos alunos que, a partir de novos conceitos, conseguem se ancorar nos conceitos existentes para avançar em novas compreensões (MOREIRA, 1999). O aluno (A3) argumenta que as questões fazem sentido e isso revela um indício de que o material trabalhado no aplicativo é potencialmente significativo de acordo com a teoria de Ausubel (1978), assim como o aluno (A2) afirma que o seu interesse aumentou, pois fica na expectativa de chegar à resposta correta.

Por outro lado, os $15 \%$ que responderam NÃO, demonstram em seus argumentos que possuem dificuldades de entender e relacionar os conteúdos. $\mathrm{O}$ aluno (A5) não consegue estabelecer as mesmas relações que os seus colegas de grupo, assim como o aluno (A6) que não consegue olhar o que a maioria de seus colegas "vê". O aluno (A7) não consegue resolver questões com cálculo. Esses três alunos apresentam argumentos que indicam a ausência de subsunçores necessários para alavancarem os conhecimentos existentes em outros de maior complexidade. Ao contrário do aluno (A4) que afirma ser um bom aluno e sempre tirar "DEZ", afirma que, por não ter dificuldades, o aplicativo não alterou a sua vida acadêmica.

Nas duas questões seguintes, os alunos entrevistados responderam aos aspectos positivos e negativos. Os que responderam aos aspectos positivos, não responderam aos aspectos negativos e vice-versa como podemos ver nas tabelas 2 e 3 , respectivamente.

TABELA 2. Segunda questão com percentual de respostas dos aspectos positivos

Pense nos aspectos que você considera como POSITIVOS sobre o Socrative nas aulas de física e comente-os. $(90 \%)$ 
V Congresso Brasileiro de Informática na Educação (CBIE 2016)

Anais do XXVII Simpósio Brasileiro de Informática na Educação (SBIE 2016)

(A8) O Socrative não deixa a gente se desconcentrar. A gente fica na maior expectativa de saber a resposta de um problema e isso, nos deixa mais atentos na hora de resolver os exercícios.

(A9) O Socrative nos força a pensar mais na questão e isso não acontece quando temos uma lista de papel, pois logo em seguida passamos para outra questão se não conseguimos resolver a anterior. Às vezes, se tem dez questões na lista de papel, lemos as dez para depois tentar resolver alguma. Acho que a gente desiste fácil quando se trabalha assim. No Socrative, como não podemos pular a questão, a expectativa da resposta é o que nos faz tentar acertar.

(A10) O Socrative faz a gente usar o celular para aprender. A gente pode pesquisar na internet e ver como se faz as coisas. Na internet tudo é mais rápido. E o aplicativo ajuda o professor a ver o que estamos fazendo para nos ajudar.

(A11) Me sinto familiarizada com o aplicativo. Nunca pensei que um aplicativo iria me deixar mais ligada na aula. Meu interesse aumentou porque meu estilo de vida é ter um celular na mão e um monte de ideias na cabeça...hahaha. Eu vivo no celular, tenho tudo que quero no celular. O celular faz parte do meu corpo e até da minha mente. A minha agenda, os meus compromissos, as minhas redes sociais, e-mails e até os meus prazeres como musicas e vídeos estão no meu celular.

Os alunos (A8) e (A9) apresentam argumentos próximos quanto à atenção. Há uma motivação em querer resolver as questões para conferir os resultados. Para (A8) existem uma grande "expectativa para saber a resposta de um problema", assim como para (A9) é essa expectativa que os faz "tentar acertar". Esses argumentos indicam que esses alunos têm disposição para aprender como sugere Ausubel, pois o material apresentado no Socrative os faz pensar mais nas questões, isto é, o material tem significado. Além disso, existe o engajamento previsto por Mazur (2015), pois os alunos envolvem-se com as suas aprendizagens quando são avaliados e podem confrontar as suas respostas com os colegas.

Os alunos (A10) e (A11), também confirmam as nossas inferências sobre os seus argumentos e vão um pouco mais. Satisfeitos e familiarizados com o aplicativo, apresentam em seus argumentos as motivações externas e internas sobre o uso do celular e a utilização do aplicativo. A motivação externa (ou extrínseca) ocasionada pelo celular favorece a motivação interna (ou intrínseca) para aprender. Respectivamente, destacam que o celular facilita o acesso a informações (A10) e que esse aparelho é uma extensão de seu corpo e mente (A11). Por outro lado, os aspectos negativos indicam desconforto a alguma forma de exposição perante aos colegas e ao professor.

TABELA 3. Terceira questão com percentual de respostas dos aspectos negativos

Pense nos aspectos que você considera como NEGATIVOS sobre o Socrative nas aulas de física e comente-os. $(10 \%)$

(A12) Eu acho que o professor, quer nos controlar demais, porque fica sabendo o que cada um faz e se fez. Tudo bem, eu entendo que ele quer ter um feedback imediato para nos ajudar durante a aula. Mas me sinto vigiada e isso me incomoda. Fico bloqueada e aí eu não aprendo. Acho opressor esse tipo de trabalho.

(A13) E eu sei que é possível mudar no aplicativo o que o professor não muda, aquilo de não passar para a próxima questão sem dar a resposta da anterior. Acho que o professor poderia mudar, pois nem sempre conseguimos resolver a questão daquele momento. Aí tem que ficar pedindo ajuda para os colegas próximos.

Essas respostas demonstram o desconforto dos alunos com o uso do aplicativo nas aulas. Pode-se afirmar que não é por falta de domínio do aplicativo. A aluna (A12) sente-se "vigiada" e não consegue aprender, mas faz uma ressalva afirmando que o professor tem boa intenção na utilização do aplicativo, pois "ele quer ter um feedback 
imediato para nos ajudar durante a aula". Não diferente de sua colega, o aluno (A13) quando não consegue "resolver a questão daquele momento" fica desconfortável ao ter que interagir com os seus colegas, pois "tem que ficar pedindo ajuda" para esses. Para Mazur (2015), o método Peer Instruction exige essa interação, pois é a partir do confronto de ideias que os alunos poderão ampliar as suas compreensões dos fenômenos estudados. Segundo Ausubel (1978), esses alunos não possuem disposição para aprender, uma vez que as questões elaboradas pelo professor no aplicativo possam não ser potencialmente significativas para esse pequeno grupo. Uma vez que o aluno não encontra significado no material, teremos algumas possibilidades diante da teoria ausubeliana. Primeiramente, o material não é potencialmente significativo. E, talvez, o aluno não possua subsunçores para a resolução das questões ou ainda, o aluno não tenha sentido alguma motivação. Descartamos a primeira possibilidade, pois $85 \%$ dos alunos (primeira questão) consideraram que o aplicativo aumentou o seu envolvimento e sua aprendizagem em sala de aula e ainda, 90\% dos alunos entrevistados (segunda questão) veem aspectos positivos. Em relação aos $10 \%$ (terceira questão) que viram somente aspectos negativos no uso do aplicativo em sala de aula, pensamos que são aqueles alunos que não aprovaram o método de trabalho e podem estar entre os $15 \%$ (primeira questão) que não perceberam as mudanças de envolvimento e aprendizagem.

Diante dessas análises, podemos confirmar na quarta questão o que foi visto na primeira. Enquanto na primeira questão foi questionado se o Socrative teve influência no envolvimento e na aprendizagem do aluno, na tabela 4, uma pergunta semelhante foi realizada. Entretanto, a quarta questão refere-se ao método de trabalho do professor.

TABELA 4. Quarta questão com percentual de respostas de SIM, EM PARTE e NÃO

O método de trabalho do professor favoreceu o seu aprendizado?

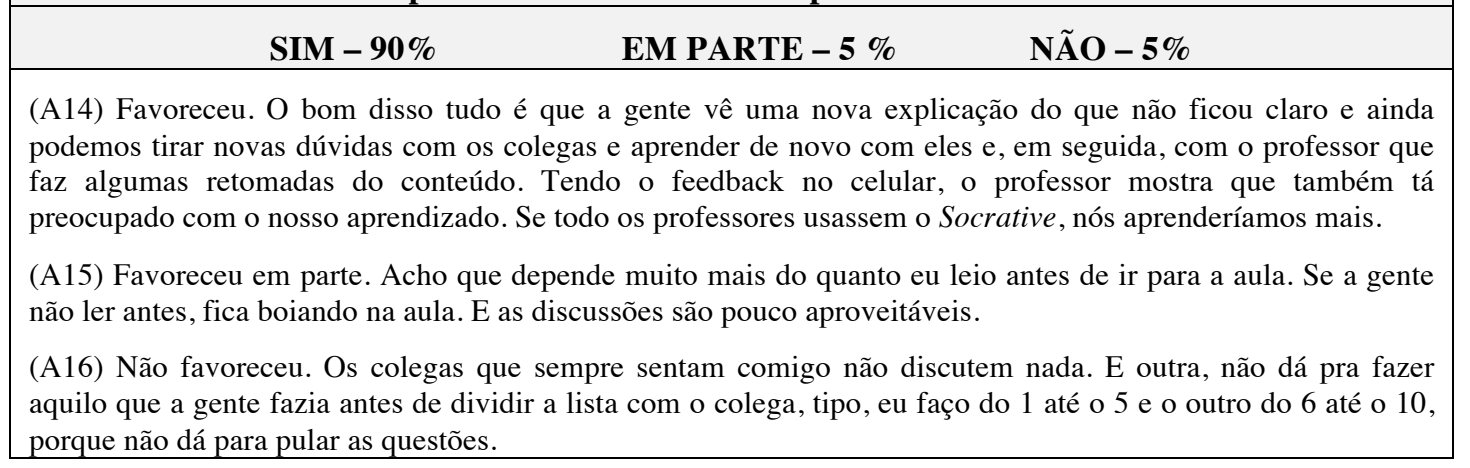

Os percentuais das respostas desta questão aproximam-se dos percentuais das questões anteriores. O elevado grau de satisfação dos entrevistados está sintetizado nas palavras do aluno (A14). Discutir e aprender com os colegas, valorizar as retomadas de conteúdo que o professor realiza em aula, além de perceber que o Socrative favorece o método, são indícios da motivação para aprender. Por outro lado, o aluno (A15) deixa claro que é preciso engajar-se, pois se não realiza as leituras, "fica boiando na aula". O aluno (A16), assim como o aluno (A13) da terceira questão passam pelo mesmo problema, o de não poder "pular as questões" que não conseguiram resolver. Para (A16), fica difícil de trabalhar com colegas que "não discutem nada". Mesmo que esses alunos tenham passado por alguma dificuldade, pode-se pensar mesmo assim que outras 
V Congresso Brasileiro de Informática na Educação (CBIE 2016)

Anais do XXVII Simpósio Brasileiro de Informática na Educação (SBIE 2016)

aprendizagens significativas ocorreram, como a tomada de consciência de que é preciso engajar-se na sala de aula e fora dela. Nesse engajamento, Mazur (2015) destaca que é necessário ler, buscar informações e enfrentar as situações e problemas que envolvem o conteúdo para ter o que discutir na sala de aula. Nesse sentido, percebe-se que a maioria dos alunos engajados fica, aparentemente, desmotivada na ausência de atividades no Socrative quando essas são realizadas com listas impressas, como podemos ver na tabela 5.

TABELA 5. Quinta questão com percentual de respostas referente aos sentimentos dos alunos na ausência do Socrative

O que você sente nas aulas em que o professor não disponibiliza atividades no Socrative, mas distribui listas impressas de exercícios? Explique.

Prefiro assim 5\% Nada, fico indiferente 5\% Não gosto 90\%

(A17) Eu não gosto. Prefiro a aula com o aplicativo porque nós conversamos mais sobre matéria e o professor explica junto. Já notei que quando temos apenas a lista, alguns colegas saem da aula e entre eles, eu mesmo. Penso em fazer em casa, eu e todo mundo. Mas nunca fazemos.

(A18) Sinto que não tenho o dever de fazer. Fico dispersa, pois sei que não estou sendo cobrada. E ainda, fico com a impressão de que o professor não está a fim de saber como a gente está indo nos exercícios.

(A19) Acho sem graça. Me sinto desmotivado e aí respondo a chamada e vou embora.

(A20) Pra mim é indiferente, não vejo isso como um problema. Mas vejo que alguns colegas ficam meio perdidos. E nessas aulas, a conversa rola direto e alguns vão embora. Poucos, como eu,

trabalham.

A partir das respostas é possível perceber que o aplicativo tem influência na motivação da maioria dos alunos. A maioria dos alunos fica desmotivada. Os alunos (A17) e (A19) preferem não ficar em aula, fato observado por (A20) que fica trabalhando, pois não utilizar o aplicativo é indiferente. A aluna (A18) argumenta que não se sente cobrada e entende que o professor não tem interesse em saber como os alunos respondem aos exercícios daquela aula. Podemos inferir, que a maioria desses alunos têm disposição para aprender, pois a ausência do material, celular juntamente e Socrative, assim como o método de trabalho, são potencialmente significativos e capazes de favorecer aprendizagens significativas.

\section{Considerações Finais}

Esta pesquisa teve como objetivo avaliar como o Socrative App, utilizando a metodologia do Peer Instruction, favoreceu o desenvolvimento de aprendizagens significativas de estudantes de engenharia em uma disciplina de física geral.

Incialmente, os dados analisados nos permitem concluir que o engajamento dos alunos com as atividades disponibilizadas no aplicativo, aliadas à metodologia de trabalho, são caminhos que apontam para o desenvolvimento de aprendizagens significativas. Ao resolverem as questões, os alunos discutem entre si os caminhos a serem tomados para alcançarem os resultados corretos. Nesse sentido, o estabelecimento de relações entre os conceitos básicos, relatados pelos entrevistados, sugere a possibilidade da existência de subsunçores ou a evolução desses para a compreensão do conteúdo trabalhado. Para tal, o material disponibilizado no Socrative pôde evoluir a partir das respostas coletadas pelo professor que, realizando retomadas de acordo com o 
V Congresso Brasileiro de Informática na Educação (CBIE 2016)

Anais do XXVII Simpósio Brasileiro de Informática na Educação (SBIE 2016)

Peer Instruction, reconstruiu as questões de forma a torná-las potencialmente significativas para os alunos por meio do feedback imediato das repostas dadas por esses.

A partir dos depoimentos dos alunos, o fato de usar o Socrative em seus celulares, durantes as aulas, contribui para o engajamento não apenas nas atividades elaboradas pelo professor e disponibilizadas no aplicativo, mas também, nas trocas de realizadas por todos os atores envolvidos na sala de aula. O aplicativo, aliado à metodologia de trabalho do Peer Instruction, torna-se ferramenta auxiliar para o professor e seus alunos, no sentido de que os rumos do processo de elaboração das aprendizagens podem ser rapidamente modificados pelo feedback instantâneo da classe.

Além disso, a utilização de dispositivos móveis, como o celular, vai ao encontro da realidade dos sujeitos da pesquisa. O celular faz parte de suas vidas como uma extensão do corpo e da mente. O aplicativo mudou a forma de vivenciar e participar da aula. Substituindo as listas impressas de exercícios, o Socrative proporciona refletir um pouco mais sobre a resposta a ser enviada pelo aluno. Essa reflexão, na maioria das vezes, é realizada com o colega ao lado e, também, com o professor quando o impasse gerado pela dúvida está presente. A partir das respostas é que o professor verifica a situação da aprendizagem da turma. Com listas de papel, o feedback seria mais demorado, pois haveria a necessidade de usar outros meios de votação, como os flashcards, cartões coloridos nos quais cinco diferentes cores representam as cinco alternativas de questões de múltipla escolha, por exemplo.

Por outro lado, poucos alunos não aprovaram o uso do Socrative. Os argumentos relacionados a essa rejeição são acompanhados de alguns poucos aspectos positivos. Isso demonstra que mesmo rejeitada pela minoria, a proposta tem alguma aceitação. Os entrevistados, entretanto, assumem que não conseguem superar algumas dificuldades, o que nos permite inferir que a rejeição ao aplicativo pode ter conexão com alguns obstáculos para o processo de aprendizagem desses.

Entretanto, a rejeição pela minoria não interferiu significativamente no aprendizado do restante dos entrevistados. Porém, os alunos adeptos da proposta demonstraram uma desmotivação quando o aplicativo era substituído por listas de exercícios impressas e sem (ou pouca) interação do professor. Temos, nesse sentido, a compreensão de que os alunos entendem que a ausência do aplicativo implica em ausência (total ou parcial) do professor na sala de aula para avaliar e participar das aprendizagens que estão sendo elaboradas pela turma.

Finalizando, concluímos que o Socrative é uma importante ferramenta auxiliar para o ensino do professor e a aprendizagem de seus alunos. Porém, é preciso salientar que o aplicativo é apenas um software e que sem uma metodologia planejada e apropriada ao ensino, não é garantia de aprendizagens significativas. Nesse sentido, para que o professor possa elaborar um material potencialmente significativo, torna-se necessária a realização de diagnósticos dos conhecimentos prévios dos alunos, a partir do feedback instantâneo enviado por cada estudante através de seus celulares ou tablets. Nesse formato de aula o professor pode organizar questões significativas e interagir com os seus alunos de acordo com os princípios do Peer Instruction.

Esta pesquisa com o Socrative App não está finalizada. Pretendemos, a partir do próximo ano, investigar o aplicativo nos domínios da neurociência. Nossa ideia é 
V Congresso Brasileiro de Informática na Educação (CBIE 2016)

Anais do XXVII Simpósio Brasileiro de Informática na Educação (SBIE 2016)

verificar o comportamento da atividade cerebral em situações com e sem o aplicativo para a resolução de problemas. Nesse sentido, utilizaremos aparelhos portáteis de eletroencefalograma (EEG) disponíveis em sites especializados e de valor acessível que podem ser conectados a um computador ou um dispositivo móvel. Uma hipótese inicial vai ao encontro de estudos relacionados (FEUERSTEIN, 1980; SCHACTER, 1996; SCHULTZ, 2007) que destacam a atuação da dopamina, um neurotransmissor responsável por sensações de prazer, atenção e cognição, entre outros, que entra em ação por motivações internas e externas aos indivíduos.

\section{Referências}

Alencar, G.A., Pessoa, M.S., Santos, A.K.F., Carvalho, S.R.R., Lima, H.A.B.L. (2015). "WhatsApp como ferramenta de apoio ao ensino". Anais dos Workshops do IV Congresso Brasileiro de Informática na Educação (CBIE).

Araujo, I.S. e Mazur, E.(2013). "Instrução pelos Colegas e Ensino sob Medida: uma proposta para o engajamento dos alunos no processo de ensino-aprendizagem de física”. In: Caderno Brasileiro de Ensino de Física v. 30, n. 2: p. 362-384, ago.

Ausubel, D. (1978). Psicología Educativa: Um punto de vista cogniscitivo. México: Editorial Trillas.

Feuerstein, R. (1980). "Instrumental enrichment: an intervention program for cognitive modifiability”. Baltimore: University Park Press.

GIL, A. C. (2007). Como elaborar projetos de pesquisa. 4ª ed. São Paulo: Atlas.

Honorato, E., Schocair, C., Quadros, J., Castaneda, R., Soares, J., Mauro, R., Duarte, R., Ogasawara, E.,. (2015). "Explorando uma Aplicação m-learning para Ensino de Vetores na Física do Ensino Médio". Anais dos Workshops do IV Congresso Brasileiro de Informática na Educação (CBIE).

Mazur, E. (2015). Peer Instruction: a revolucao da aprendizagem ativa. $1^{a}$ edição. São Paulo: Artmed.

Moran, J. (2013). “Caminhos que facilitam a aprendizagem”. In: Novas Tecnologias e Mediação Pedagógica, Papirus, $21^{a}$ ed., p. 27-29.

Moreira, M. A. (1999). Aprendizagem significativa. Brasília: Editora Universidade de Brasília.

Schacter, D. L.(1996). "Searching for memory: the brain, the mind and the past". New York, NY: Basic Books.

Schultz W. (2007). "Multiple dopamine functions at different time courses". In: Annual Review of Neuroscience, V. 30: 259-288.

Valente, J.A. (1999). O computador na sociedade do conhecimento. Campinas, SP: UNICAMP/NIED, 156p.

Yin, R.K. (2010). Estudo de caso: planejamento e métodos. Porto Alegre, Bookman. 